\title{
NUCLEAR EXCAVATION EFFECTS
}

Review: Airblast Effects

Jack W. Reed, Sandia Laboratories

I. Long Range Airblast Propagation

On February 2, 1951, the Atomic Energy Commission discovered that airblast from an 8-kt explosion could break many windows in Las Vegas at 60 miles range from Frenchman's Flat. Yet later, on February 6, only minor effects resulted from three times as large a yield. Atmospheric conditions were found to be responsible for this apparent anomaly. A weather watch was initiated under the direction of Everett Cox to help prevent recurrences during further atmospheric nuclear testing.

Our atmosphere with its stratifications of temperature and winds acts as an acoustic lens which may trap, duct, or even focus blast waves from explosions. The basic refraction mechanism is described by Figure 1 . Sound speed is proportional to the square root of absolute temperature, as shown in Newton's Principia, so as temperature decreases with altitude, so does sound speed. The proper coefficient was found by Laplace, using adiabatic rather than Newton's isothermal compression. Sound or blast waves propagate through moving air with this wind added or subtracted from the sound speed. This affects an initially vertical plane wave to make it increasingly distorted with time. Wave normals, or rays, are bent upward, away from ground, in layers where net sound velocity decreases with altitude and are bent downward where sound velocity increases with altitude.

This bending, applied to a point sound source or explosion, gives ray paths typified by Figure 2 . Where ducting is caused by a velocity inversion high above the ground, there is a zone of silence beyond the immediate range of the strong explosion wave, and a sound ring at some distance determined by the height and strength of the ducting layer.

Calculation of ray paths has evolved with the growth in needs and computer capabilities. A 1912 model by Fujiwhara, at the Tokyo Central Meteorological observatory (1), was quite complete. Rothwel1 (2) in 1947 provided the system of equations used for the first nuclear test predictions, by desk calculator, in late 1951. Techniques were speeded up by hand calculation methods of Cox, et al (3), and used with an analogue computer built in 1955 at Sandia by Durham (4). Modern computer capabilities now allow a complete acoustic solution, without simplifying assumptions about wind effects, from Thompson's program $(5,6)$, for $1^{\circ}$ ray elevation angle increments, in several azimuth 


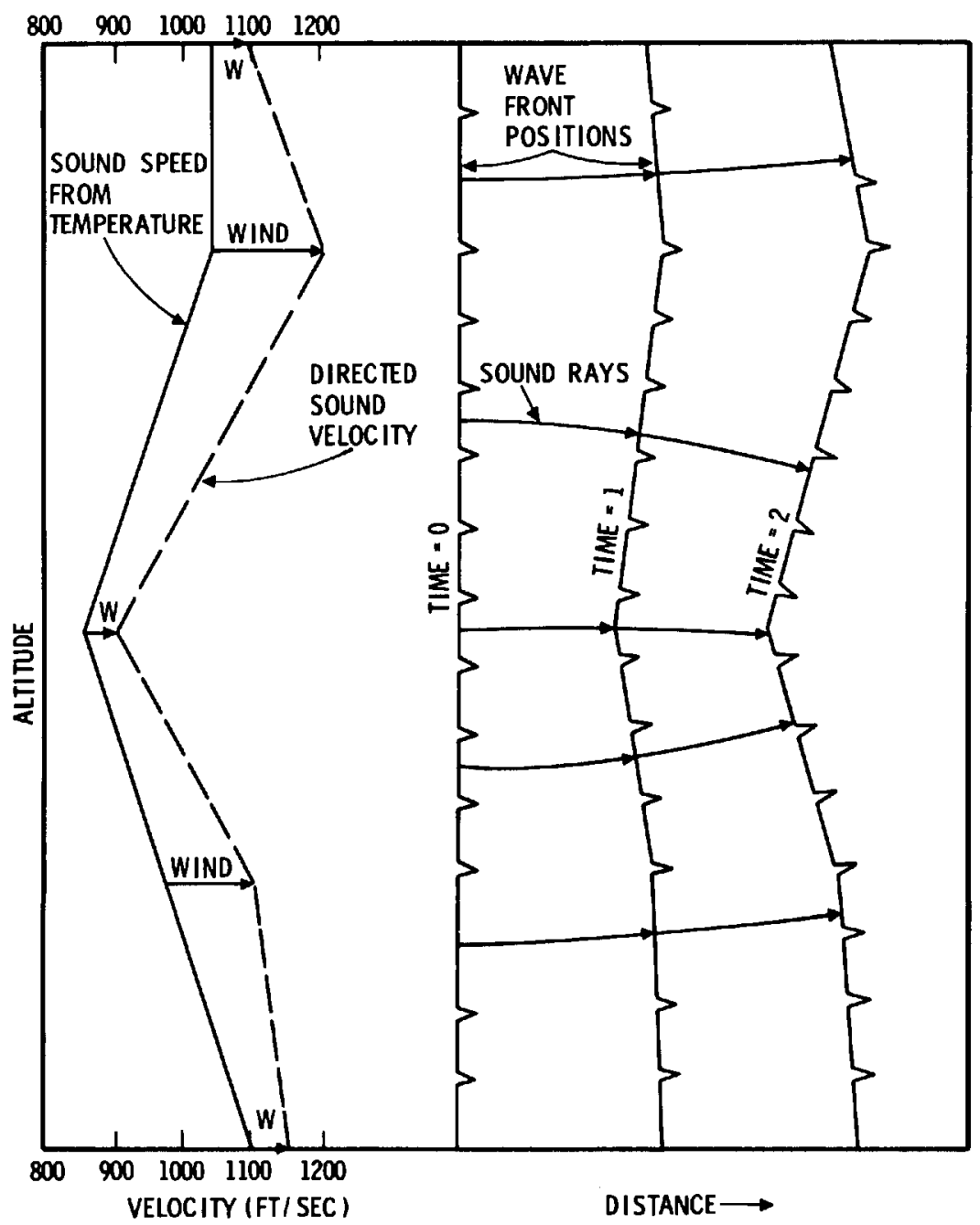

Fig. 1 Shock-Wave Distortion by Layered Atmospheric Temperature and Wind Structure.
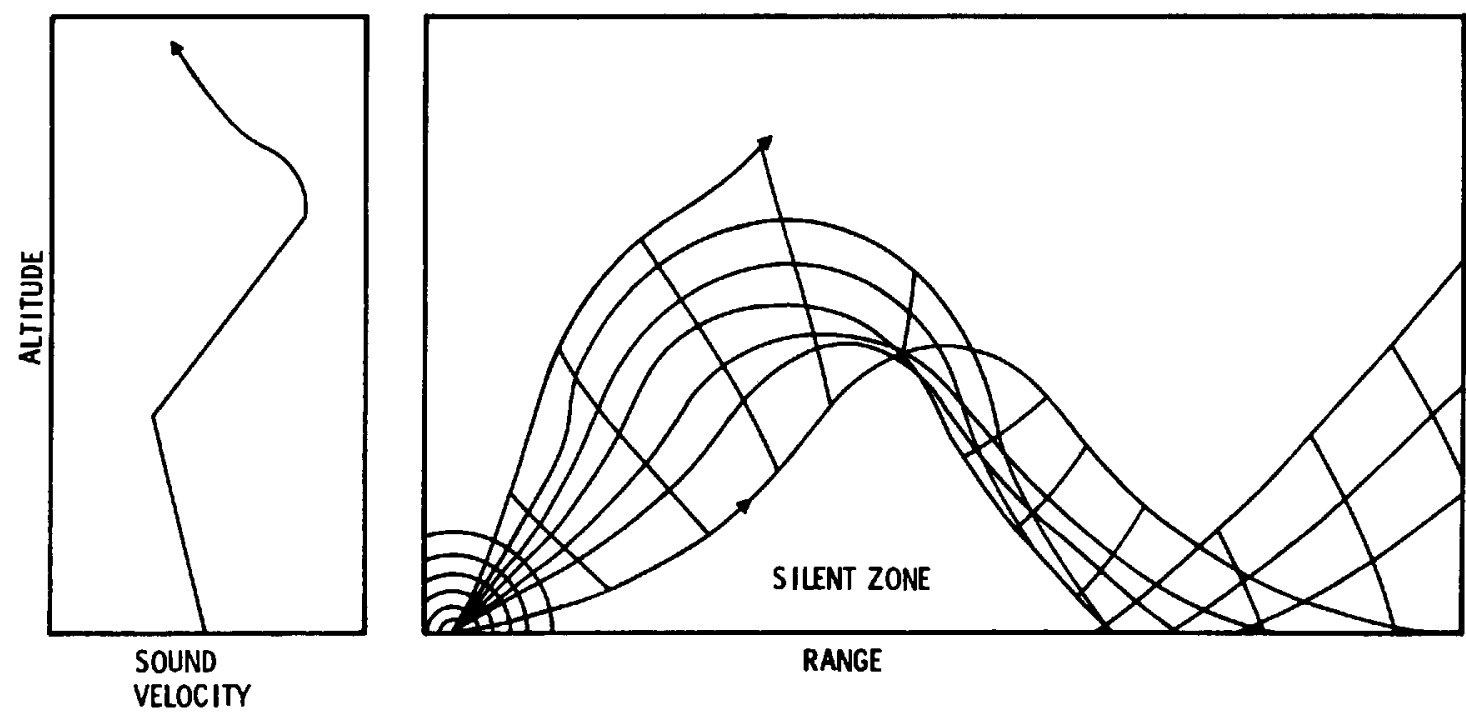

RANGE

Fig. 2 Typical Explosion Ray Paths. 
directions, through $200,000 \mathrm{ft}$. of observed atmospheric layers with gradients in both temperature and vector wind, in less than a minute on a CDC-3600. [Nevertheless, current periodicals contain several papers per year showing ray calculation programs which apparently were generated from digitizing the equations in the Dover Edition ( 7 ) of Lord Rayleigh's classical text. Most even assume homogeneous layers and overcome this deficiency by dividing the atmosphere into almost an infinity of infinitesimal layers, to fully use their computer capacity and help justify its acquisition. ]

When there is a strong night-time temperature inversion, or equivalent low-level wind structure, as shown in Figure 3, there will be a continuous and enhanced blast pattern. Such inversions seldom extend beyond the $1500 \mathrm{ft}$. thick boundary layer. These propagations from NTS have been blocked or at least attenuated by the mountains which surround the test basins. Over flat terrain this inversion effect must be considered. A solution to the wave equations for this type of ducting has been obtained in the form of Airy Waves, by Byatt and Devault (8), but it has not been computer programmed or experimentally verified for lack of urgency in applications.

According to Cox, et al (9), the RANGER incident of 1951 was caused by jet stream winds, as shown by a similar pattern in Figure 4, which caused ducting above 20,000 ft. altitudes, and focusing at some range between 12 and 25 miles. This wave was almost perfectly reflected by the ground and repeated its atmospheric path several times until it struck Las Vegas. Only one other nuclear airburst was fired with strong northwest winds, on November 2, 1951, and results confirmed the theory. Four large plate windows were smashed, others were cracked, on Fremont Street, and boxes of china were knocked from shelves at the Desert Inn, according to newspaper accounts (10).

A11 other distant blast damages from later tests were caused by ducting at much higher altitudes, in the ozonosphere near 150,000 ft. altitude, as shown by Figure 5 . There is a warm layer centered near that altitude according to the U. S. Standard Atmosphere (11), so that even moderate wind speeds will cause ducting toward downwind directions. The blast ring usually strikes at 70 to 150 miles range. Fairly steady winds to 150 knots speed blow with seasonal directions at these high altitudes, from west in winter and from east in summer. Atmospheric magnifications and test yields were only occasionally both large enough to cause damage from this ducting. This was fortunate because sounding rockets were only developed in 1958 to measure these high-altitude conditions, after most of the large NTS atmospheric tests were completed. We could not have made predictions from measured atmospheric data and acoustic ray path calculations for earlier tests.

The pressure pulse signature from an explosion, at short range, is shown in Figure 6 . After long travel through the atmosphere, with its various layers and turbulence, the 


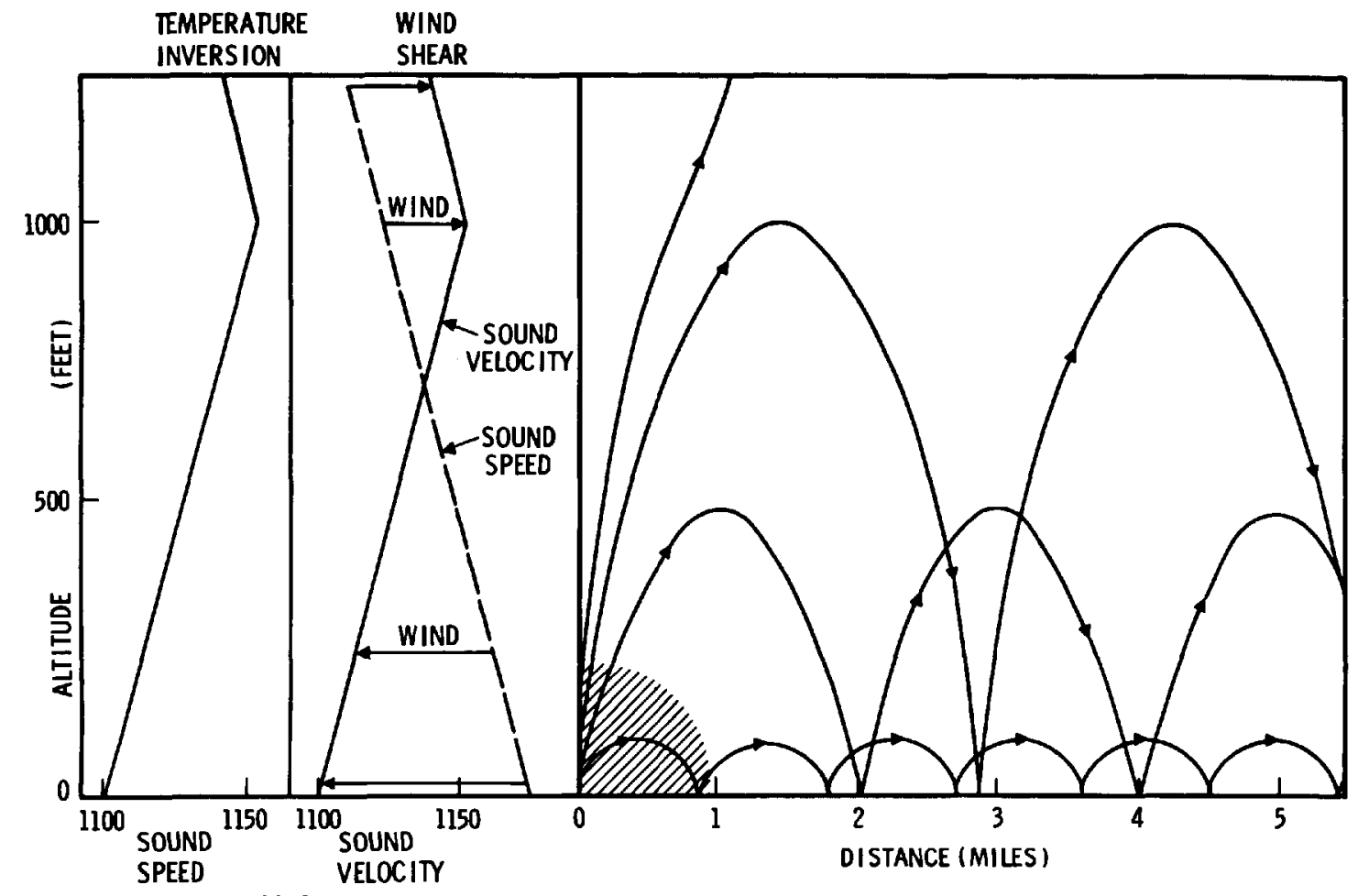

F. / SEC.

Fig. 3 Surface Inversion Sound Ducting.

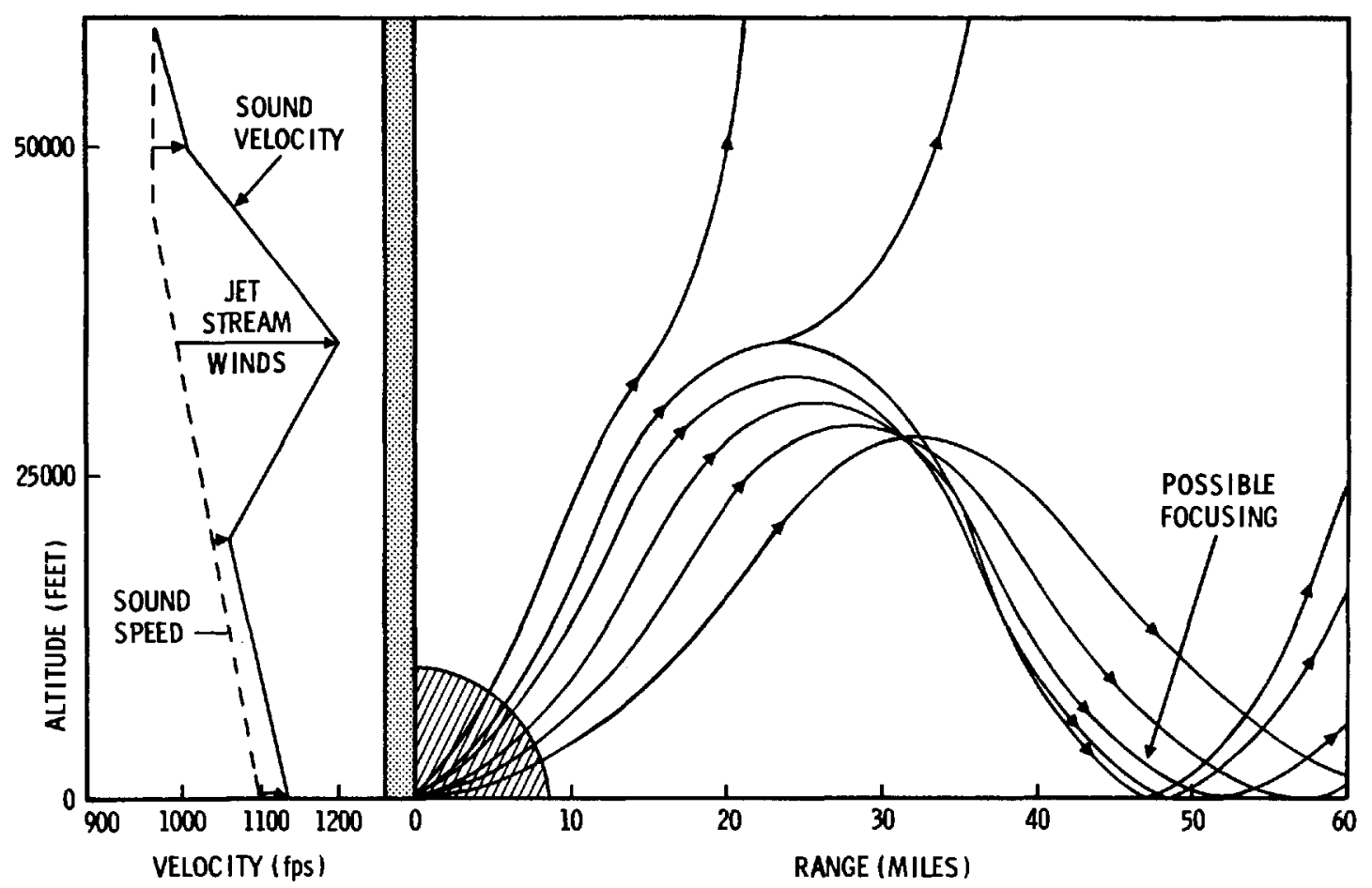

Fig. 4 Jet-Stream Sound Ducting. 


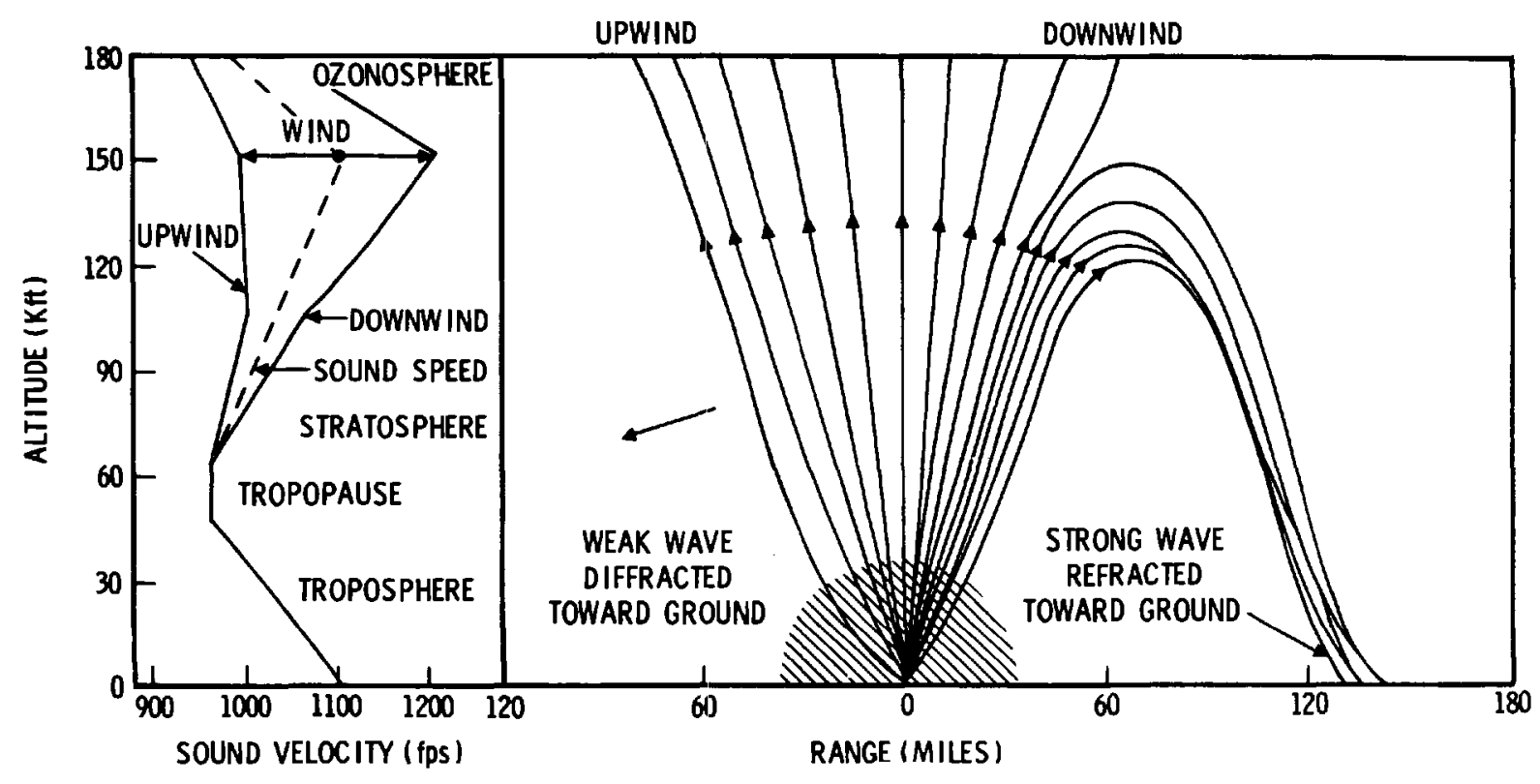

Fig. 5 Ozonosphere Wind Effect on Sound Ducting.

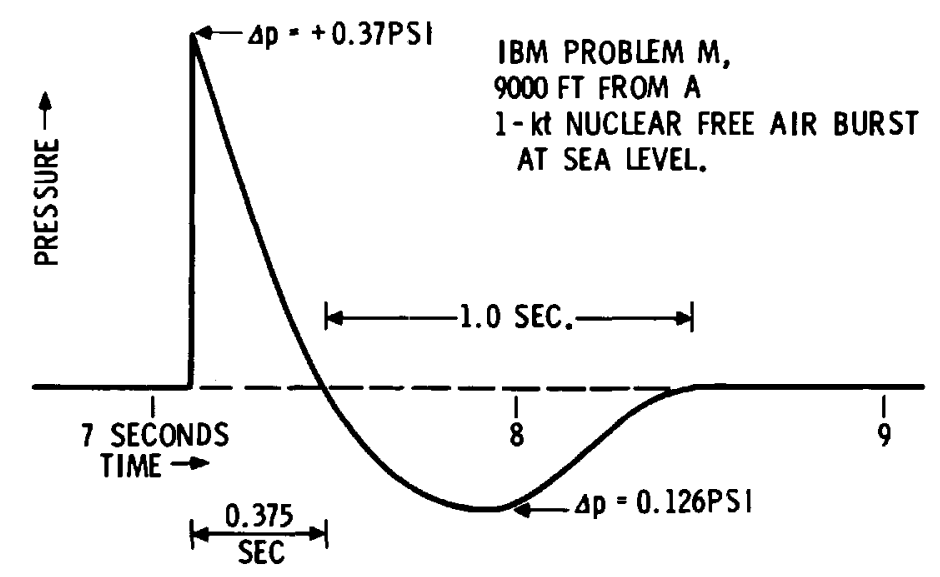

Fig. 6 Explosion Wave Pressure-Time Signature. 
wave usually arrives as a rumbling of several cycles. Occasionally some of the classical waveform is preserved and loud bangs may be heard. Positive phase duration is usually two to four times as long as at close-in ranges, and near five seconds per cycle for $10 \mathrm{kt}$, but still in the range which may cause resonance in very large windows. Phase durations increase in proportion to the cube root of larger yields following Sachs (12) scaling, or A-scaling as described in The Effects of Nuclear Weapons (13).

Airblast standard overpressures are shown in Figure 7 , for some distances of concern to off-site safety predictions. To $9000 \mathrm{ft}$. from 1-kt the hydrodynamic calculations, IBM Problem $M$, is used for a homogeneous, calm atmosphere at sea level pressure. This calculation was made at Los Alamos by Porzell, based on derivations by Bethe and Fuchs, but results are compiled in a report by Broyles (14). Scaling laws are shown for distance and time, with constant shock strength, $\Delta \mathrm{p} / \mathrm{p}$. These laws are used for adjustment to other yields and pressure altitudes. Beyond the hydro-calculation a power law decay is assumed, that $\Delta p \sim \mathrm{R}^{-1.2}$, which also gives $\Delta \mathrm{p} \sim \mathrm{w}^{0.4}$ under the scaling 1aws. This decay was empirically determined from the Banshee experiments, at White Sands Missile Range in 1961 (15), with vertical propagations from $500 \mathrm{lb}$. HE bursts, and at Sandia with $1 \mathrm{lb}$. $\mathrm{HE}$ bursts. These were not distorted by refraction in the horizontally. stratified atmosphere. It was also reasonably well confirmed by Reed (16) at PRAIRIE FLAT by comparison of propagations from different yields ( 1.2 ton and 500 ton $\mathrm{HE}$ ) fired close in space and time to approximate equal atmospheric distortion. This experiment was conducted at Suffield Experiment Station, Alberta, Canada, in August 1968. We operated 18 microbarographs at one and two mile separations at ranges from 119 to 141 miles.

Recently more extensive hydro-calculations have been carried out to lower overpressures by Whittaker at AFWL (17) and by Lehto and Larson at NOL (18). These show lesser slopes like $\Delta \mathrm{p} \sim \mathrm{R}^{-1.12}$, but they sti11 neglect attenuation of high frequencies by the low ozonosphere air densities, opposing reshocking effects, and air turbulence, so there is no overwhelming benefit to warrant making this minor change in prediction procedures at this time. There is concern with extrapolation to large Plowshare yields, so both theoretical and experimental refinements are being attempted to gain insight into the real decay laws, to provide more satisfying formulations for this important element of prediction.

Standard overpressures, scaled for planned yield, give amplitudes versus distance for propagation in a calm, homogeneous atmosphere. Acoustic calculation gives predictions of infinite magnification at caustics or foci, which cannot be correct, but the degree of reduction has not been satisfactorily obtained from theoretical analyses of the problem. Several attempts, by Viacelli at LRL (19), Seckler and Keller (20), and Barash (21), to name a few, have given differing results. The real atmosphere causes empirically determined refractive magnifications, or divergences, for 
explosion waves, as shown in Figure 8, where values are multipliers on the standard overpressure. In practice, recorded peak-to-peak amplitude is usually reported for the noisy, quasi-sinusoidal waves at long range. For this, overpressure is multiplied by 1.35 to give peak-to-peak amplitude based on IBM Problem $M$, as shown earlier by Figure 6, and by another factor of two for ground reflection doubling as the wave strikes a ground level gage or a window pane near to ground level.

Recorded amplitude of troposphere signals versus distance curves for nuclear test series in the $1950^{\prime} \mathrm{s}$ are shown in Figures 9-12. Amplitudes have been normalized to 1-kt free airbursts, and height-of-burst effects have been removed. The scatter results from differences in atmospheric refraction effects on propagation.

The annual cycling of ozonosphere signal amplitudes is best displayed by comparing records from St. George, Utah, and Bishop, California, in Figures 13 and 14. These data are also normalized for yield and height-of-burst. Maximum propagation goes east to $S t$. George in winter, west to Bishop in summer. These stations were at about 135 miles range. At the shorter range of Boulder City, shown in Figure 15, seasonal cycling is not so pronounced. At Las Vegas, in Figure 16, it is hardly noticeable. These closer stations are usually in the calculated silence zone, short of the range of ray arrivals calculated by atmospheric ray tracing. What they do get is noise scattered or diffracted down from the stronger wave passing overhead. This scattering effect is probably caused by partial reflection from either atmospheric layers with locally large vertical sound velocity gradients and wind shears, or cells of turbulence, sometimes called turbulons, where temperature and wind may vary from the mean for the layer. It is not much influenced by the season or upper winds but appears to be mostly determined by the temperature inversion and associated wind shears and turbulence near $100,000 \mathrm{ft}$. altitudes, which apparently do not change much with season.

Seasonal direction patterns persist throughout temperate and polar latitudes but high altitude circulation over the equator and tropics is more complicated. From rocket data collected by the IOCS project, it was found by Buel1 (22) that about half of the high altitude wind variance is explained by very long secular waves, shown in Figure 17 . The predominant wave at $150,000 \mathrm{ft}$., for ozonosphere propagation ducting, has six months periodicity in agreement with results by R. J. Reed (23) for Ascension Island at $9^{\circ}$ south 1 atitude. There is a significant annual periodicity superimposed and some influence of the quasi-biennial wave may also be found. The important conclusion for tropical latitudes is that there are usually four periods each year with nearly calm conditions and minimized distant airblast ducting. There are only two such periods in temperate latitides. 


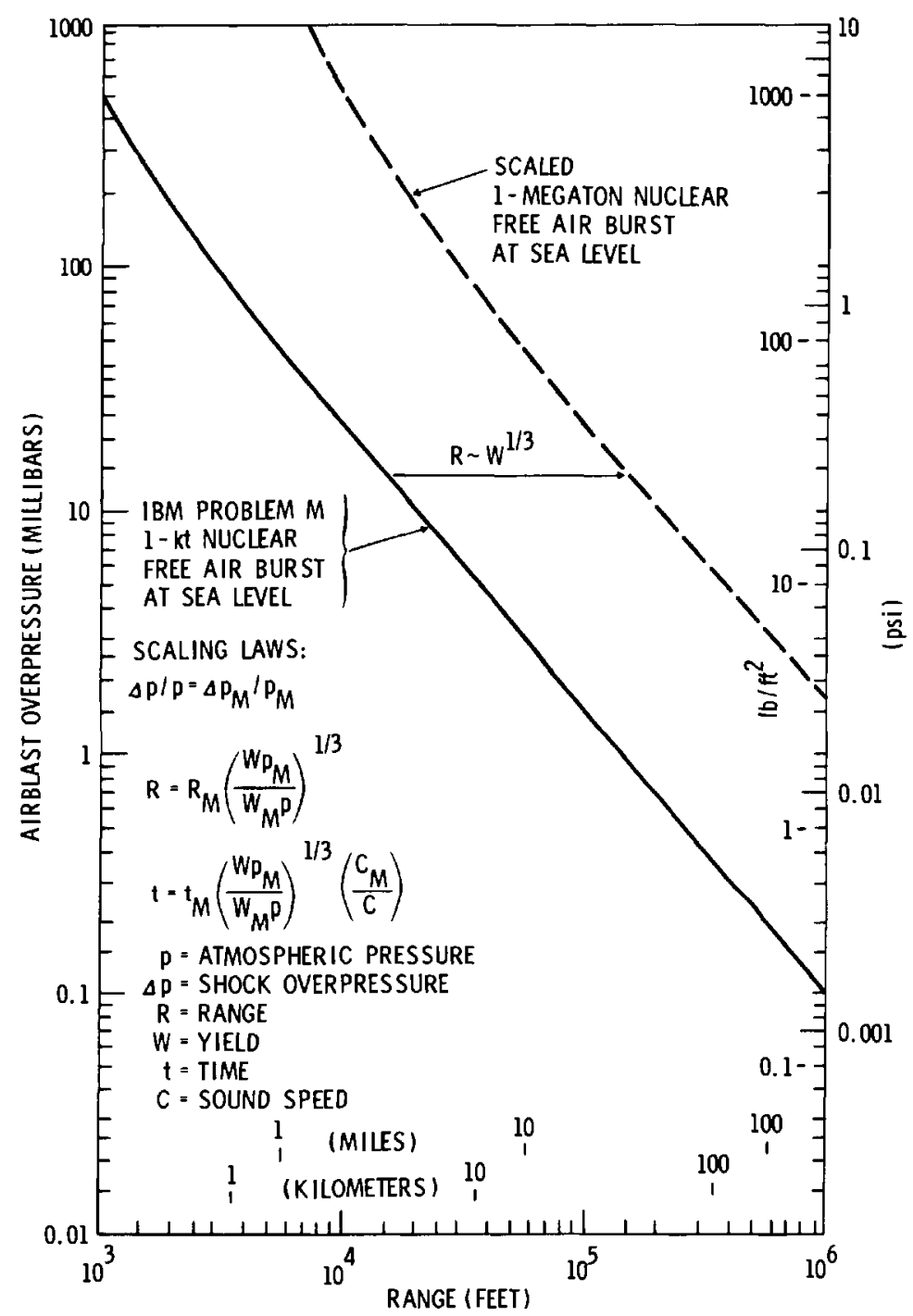

Fig. 7 Standard Explosive Overpressure-Distance Curves.

\section{ATMOSPHERIC FOCUS FACTORS}

$F=\frac{\Delta p(W ; \text { REAL ATMOSPHERE })}{\Delta p(W ; \text { HOMOGENEOUS, CALM ATMOSPHERE })}$

\begin{tabular}{|c|c|c|}
\hline \multicolumn{3}{|c|}{ FOCUS FACTORS } \\
\hline DUCTING & TYPICAL & EXTREME \\
\hline INVERSION & 2 & 3 \\
\hline JET STREAM & 1.6 & 4 \\
\hline OZONOSPHERE & 1.5 & 3.5 \\
\hline IONOSPHERE & 0.1 & 0.2 \\
\hline
\end{tabular}

Fig. 8 Atmospheric Focus Factors. 


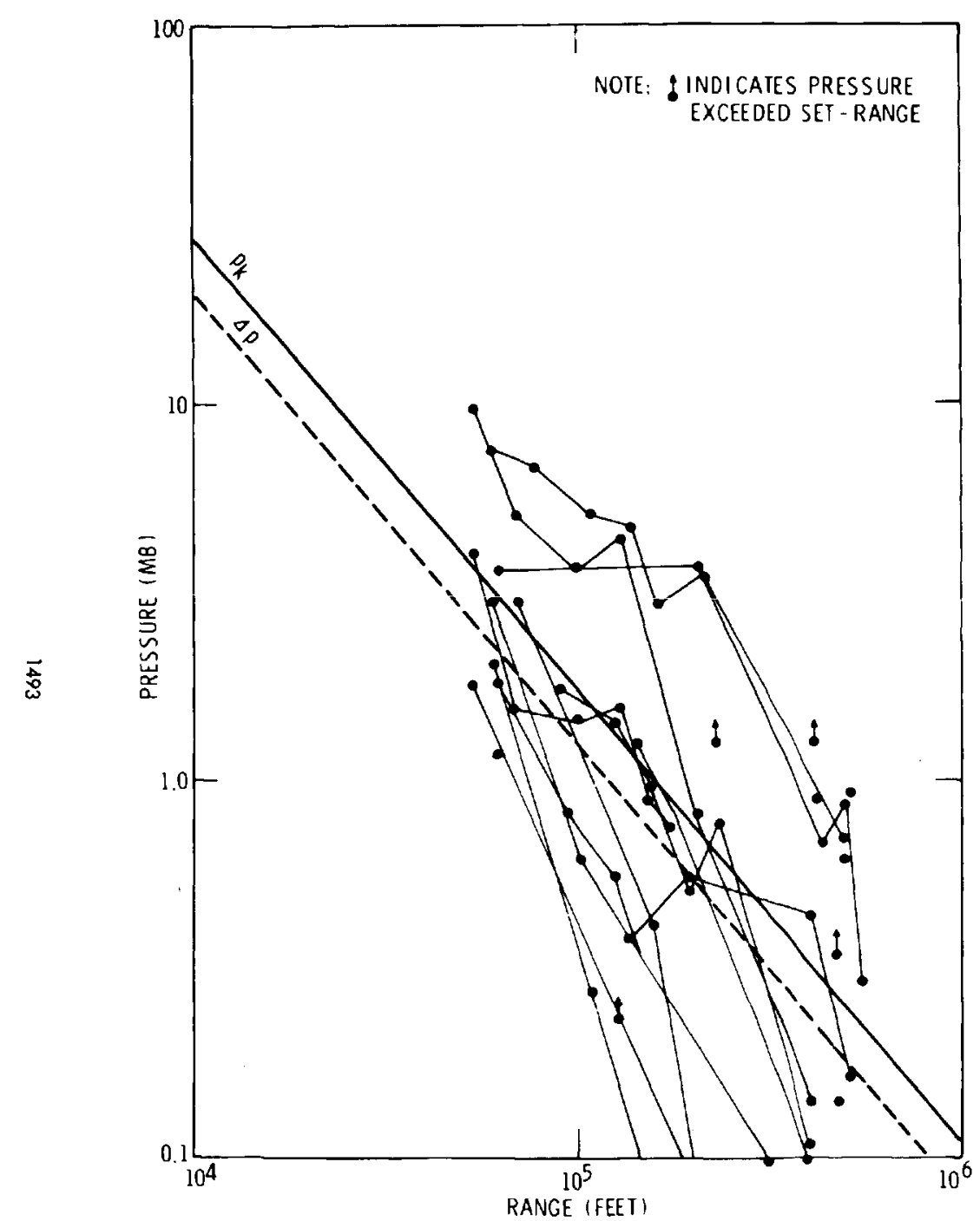

Fig. 9 Summary of Troposphere Propagations, Upshot-Knothole, 3/17-6/4, 1953.

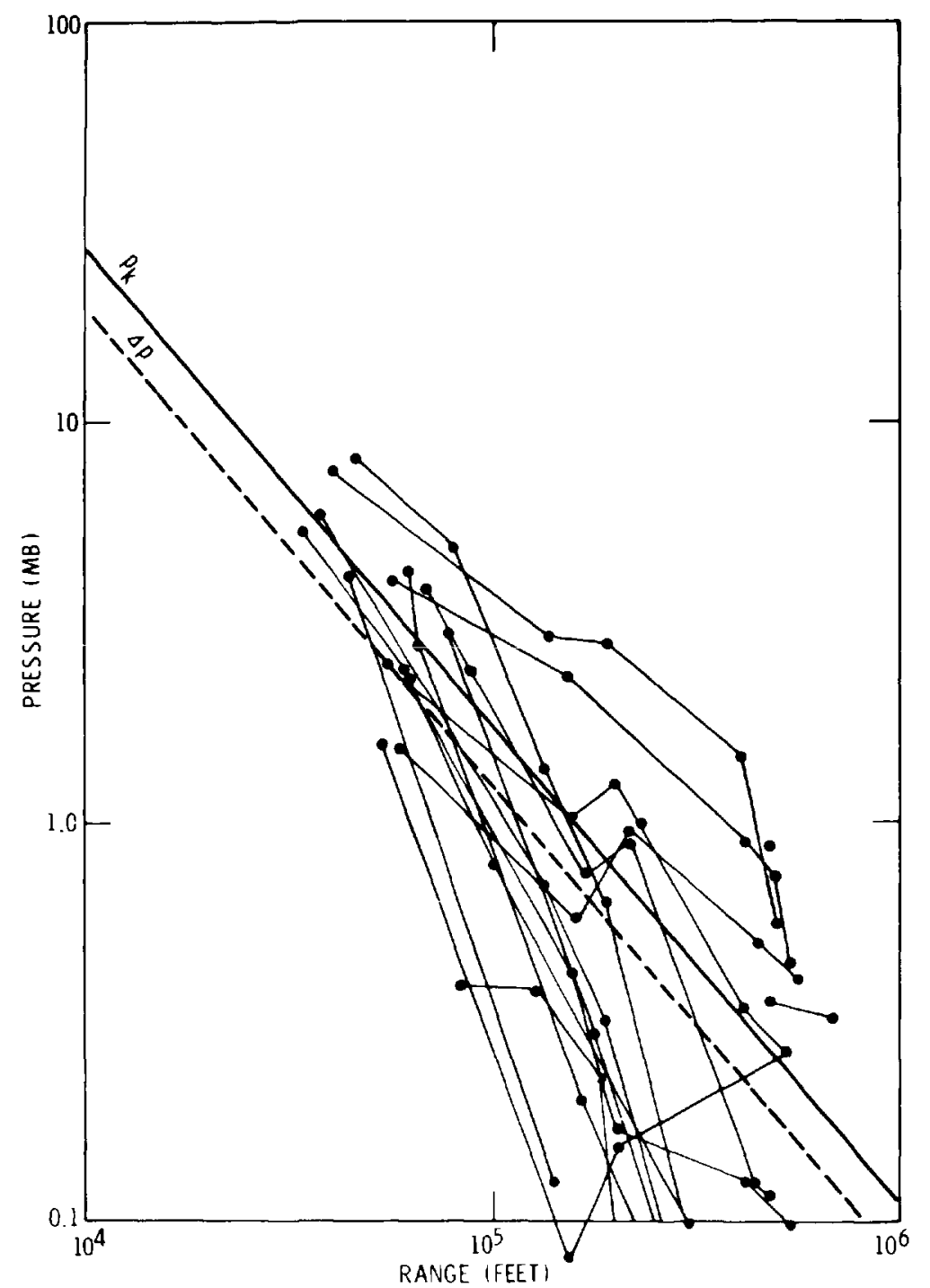

Fig. 10 Summary of Troposphere Propagations, Teapot, 2/18-5/15, 1955 . 


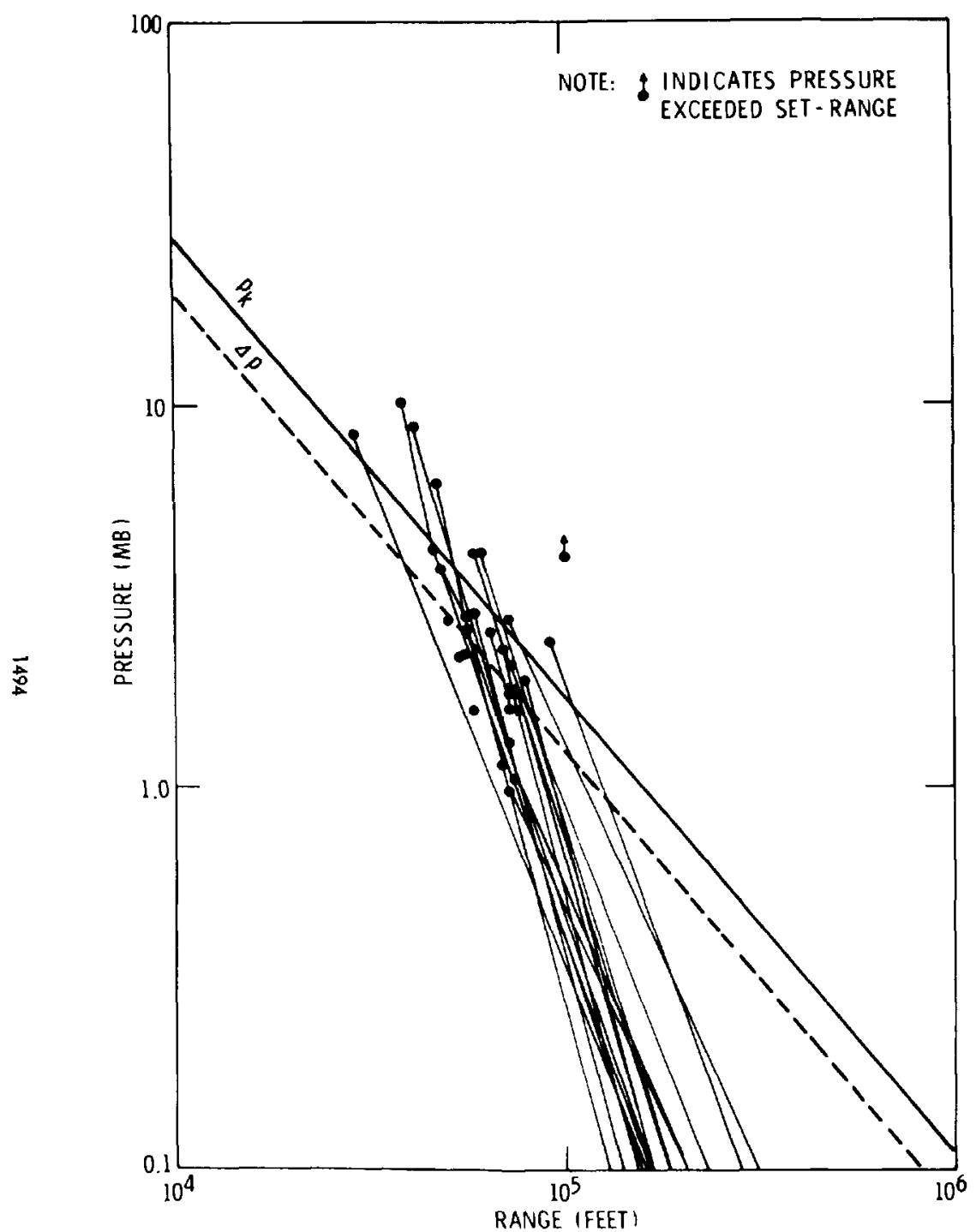

Fig. 11 Summary of Troposphere Propagations, Plumbob, 5/28-10/7, 1957.

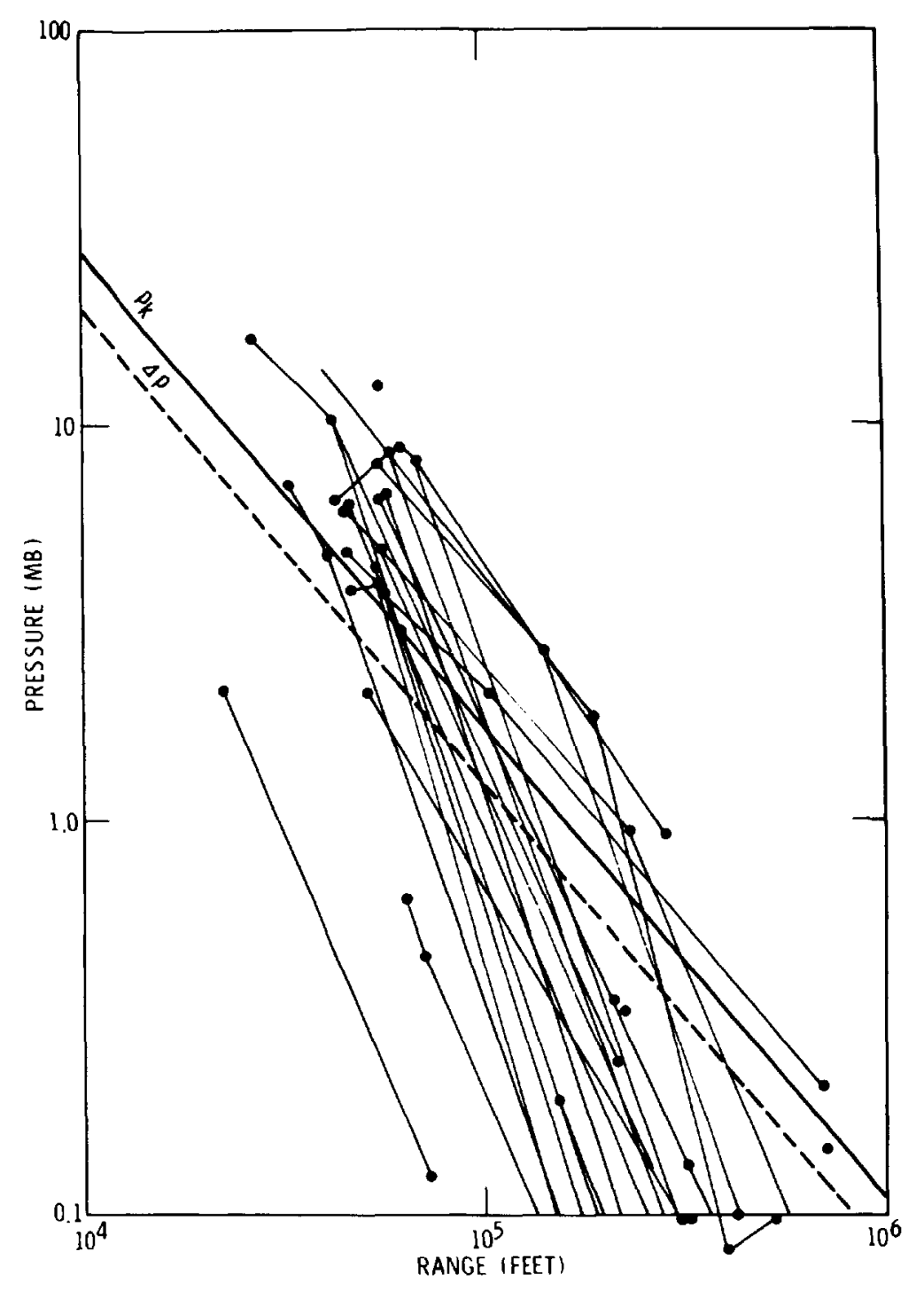

Fig. 12 Summary of Troposphere Propagations, Hardtack II, 9/19-10/29, 1958. 


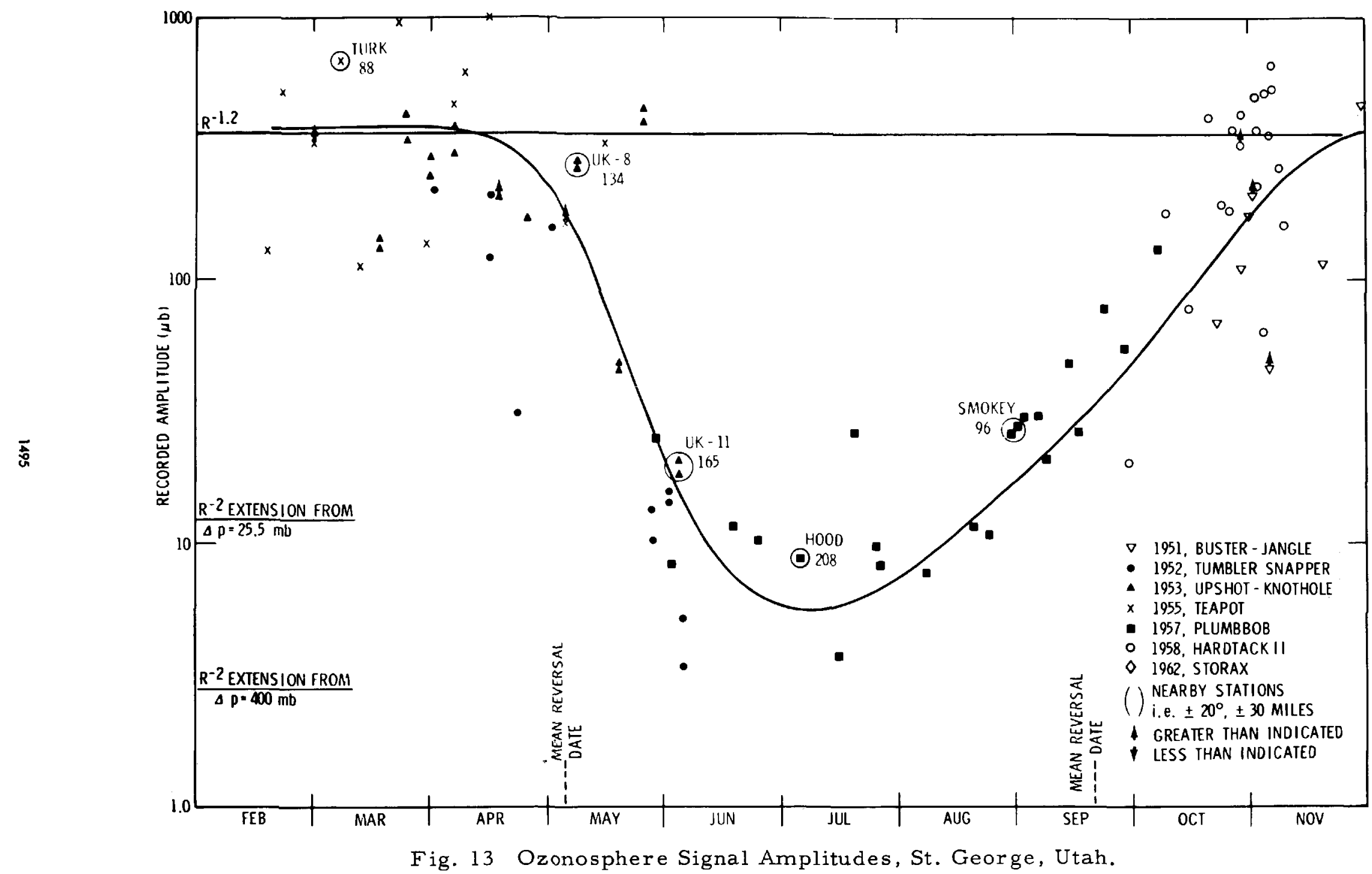




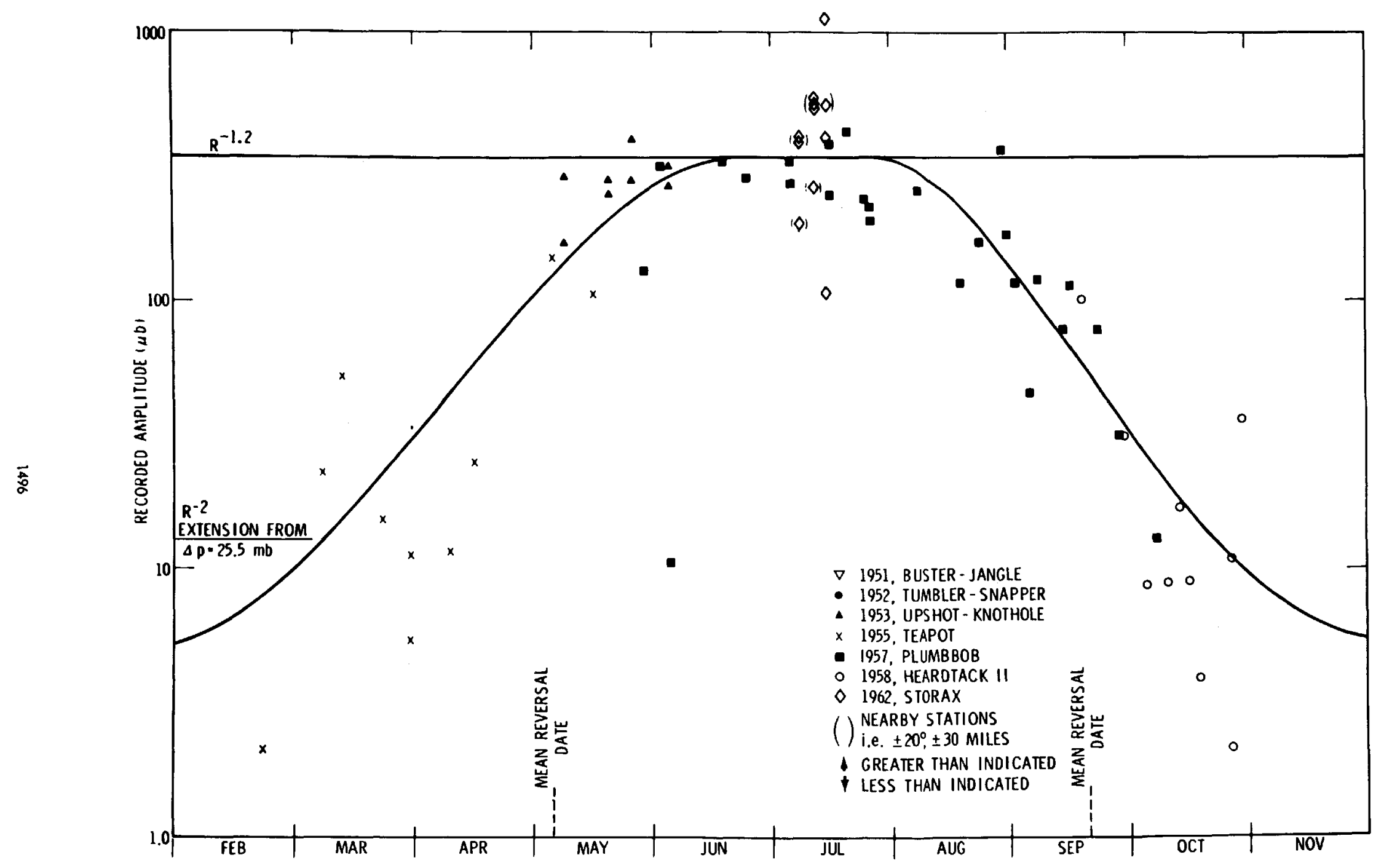

Fig. 14 Ozonosphere Signal Amplitudes, Bishop, California. 


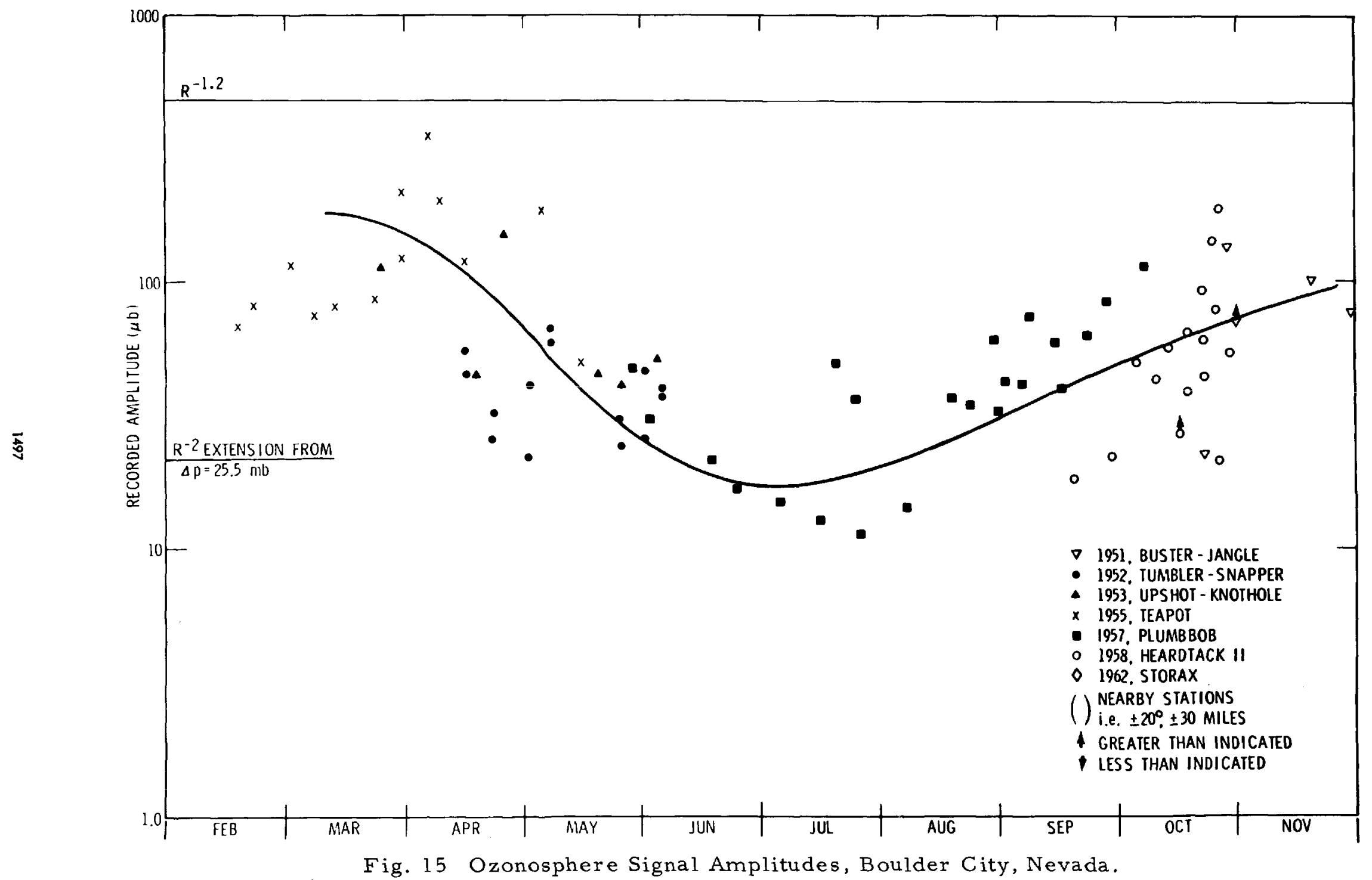




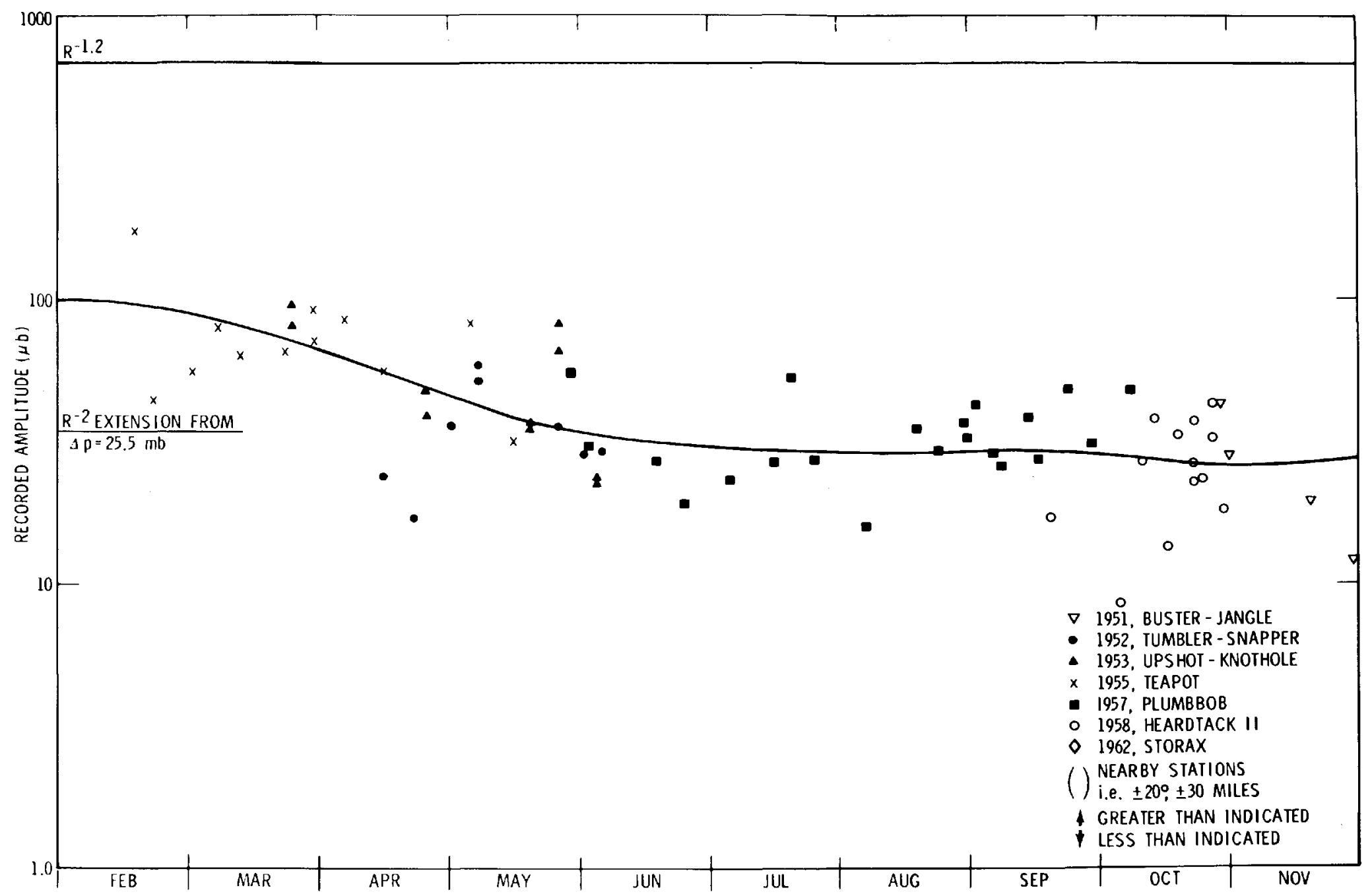

Fig. 16 Ozonosphere Signal Amplitudes, Las Vegas, Nevada. 


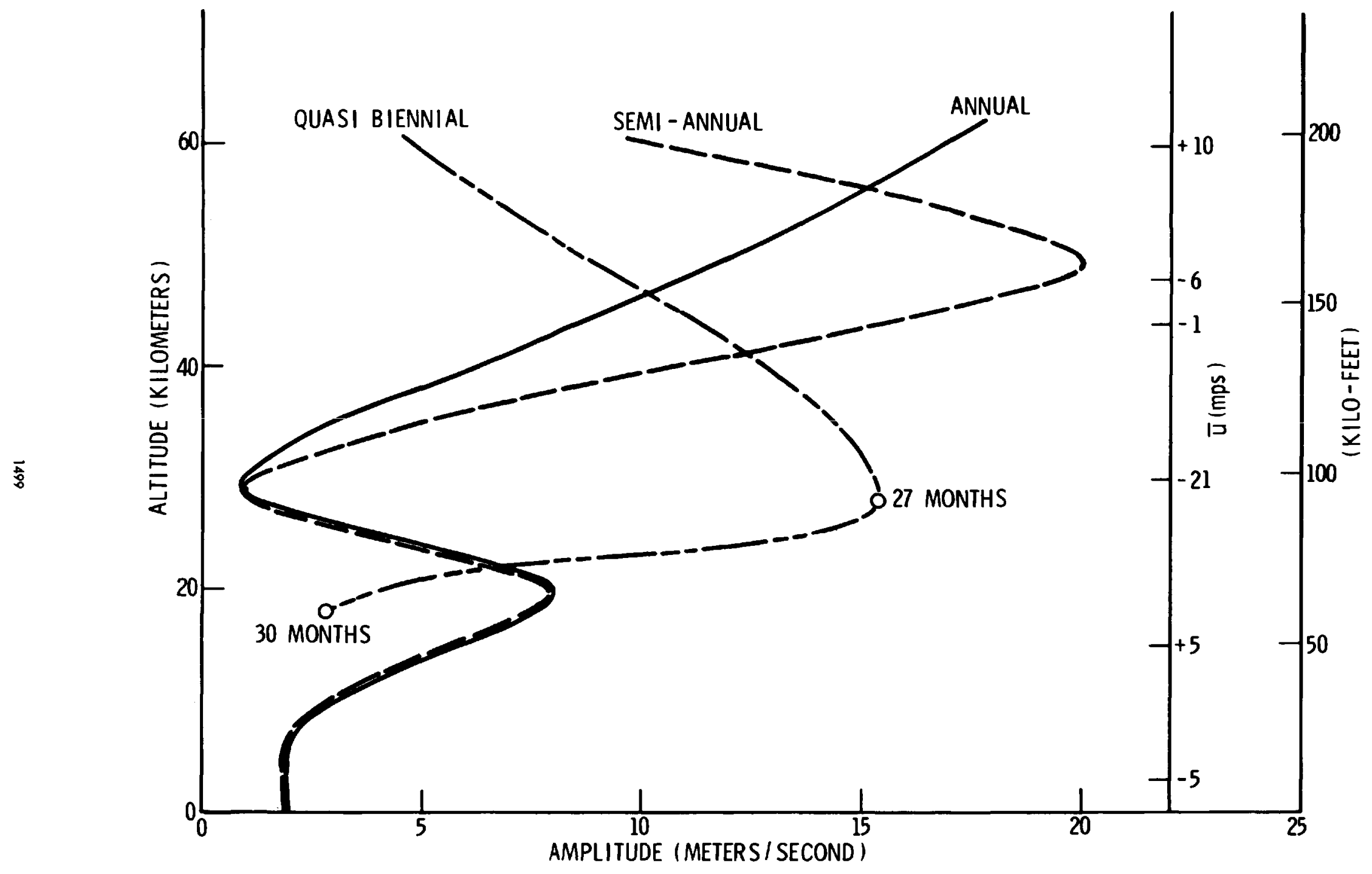

Fig. 17 Panama Zonal Wind Analysis-Secular Components per Buell, 6/23/69. 
A computer movie of the three years of rocket soundings at Battery MacKenzie, Canal Zone, has been prepared to show the oscillatory nature of these ducting zonal wind speeds.

II. Plowshare Explosives

Underground bursts give airblast waves which are in varying degrees muffled and distorted by the shot environment. As shown in Figure 18, bursts at sha11ow depths are on 1y slightly changed from the airburst character. At contained depths only a ground-shock-induced wave is coupled to the air by the piston-like mechanism of surface motion. At intermediate depths of burst, for cratering events, both ground-shock-induced and gas-venting pulses may be observed.

Piston theory reliably predicts air overpressures from contained bursts, assuming that ground motion velocities in the surface zero region are adequately predicted by the ground motion specialists--and they usually are. At minimum containment burst depths the airwave overpressure would not much exceed 1 psi at surface zero, compared to almost $100 \mathrm{psi}$ at the same distance from an airburst, so the safety problems are much reduced. The main concern is with light aircraft observing the event for any of various reasons, and they must not be exposed to more than 0.2 psi. They are usually restricted to flying at or beyond about four burst depths, or a little less overhead where ambient pressure and shock strength decreases with altitude.

Cratering events, however, can cause large enough waves to give distant damages. Their muffling may be empirically expressed by a transmission factor, shown in Figure 19. Transmissivity is defined by the ratio of overpressure, or amplitude, from the underground burst, to that expected from the same device but airburst.

Some distant observed transmission factors, for various nuclear cratering test events, versus scaled burst depth, are shown in Figure 20. There is considerable scatter and uncertainty because of the difference in geological media between these events, because of non-uniformities with direction in the gas venting eruption, and because of atmospheric variability. This last causes differences in propagation when compared to the small airburst HE calibration shots used to establish atmospheric propagation patterns. Calibration shots have been found by Reed (24) to be nonrepeatable in amplitude by factors of 1.6 , geometric standard deviation, in time separations of only a few minutes. On the average, however, this variability smooths out.

Schooner results, indicating little attenuation from burial, are probably explained by the high water content of the burst environment which gave a very large steam bubble and enhanced the gas-venting pulse. Certain explanation must await our obtaining further data from future nuclear cratering experiments and more complete hydro-calculations such as are done at LRL (24a). 


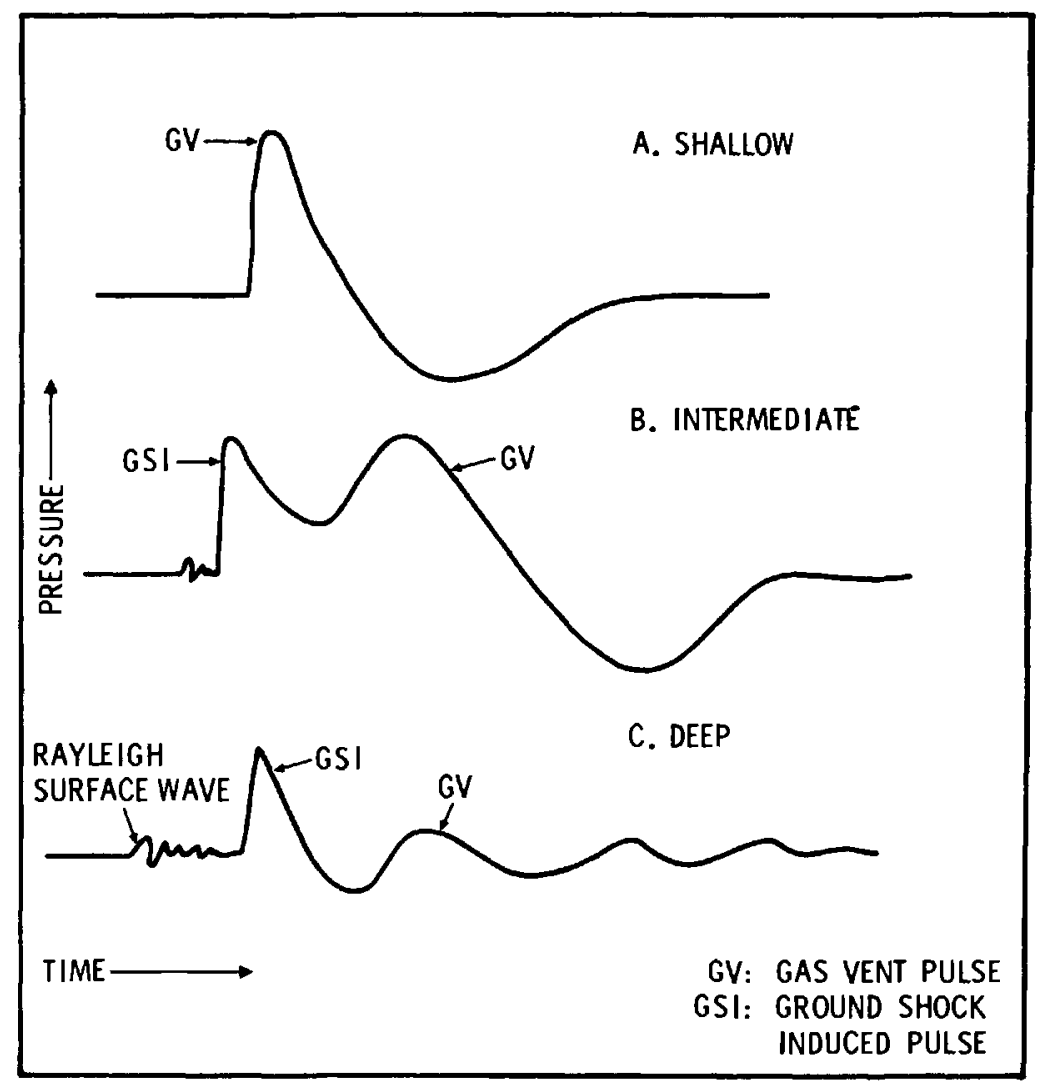

Fig. 18 Cratering Explosion Pressure-Time Signatures.

\section{TRANSMISSIVITY DEFINITION $T=\frac{\Delta p(W, \text { UNDERGROUND BURST })}{\Delta \mathrm{p}(\mathrm{W}, \mathrm{AIRBURST})}$}

Fig. 19 Transmissivity Definition. 
Even with a source model based on Schooner, however, large Plowshare excavators could be fired during periods of minimum atmospheric propagation with negotiable effects. Figure 21 shows standard recorded amplitudes versus distance for single charge 1-Mt cratering bursts near sea level. Near 135 miles range standard amplitudes, typical of downwind ozonosphere propagation, would be $6 \mathrm{mb}$ with a chance of magnification to $20 \mathrm{mb}$. This could give extensive nuisance damage, even without further increase necessary for a row charge salvo of many devices. To clearly control damage, firing during ozonosphere calm transition periods would give only $2 \mathrm{mb}$ amplitudes.

Airblast from row charges, as shown in Figure 22, is considerably enhanced in directions perpendicular to the row. Empirical data, observed at close ranges by Vortman (25), show a compromise result, between $\mathrm{N}^{0.4}$ increase with number of charges, $\mathrm{N}$, which follows from yield addition, and $\mathrm{N}$ dependence from acoustic wave addition by interference. The exponent observed is $\mathrm{NO} .7$, so that a row of ten charges causes five times the amplitude emitted by a single charge. Exercises with burst depth variations, charge spacing, and timed intervals between detonations would help to refine this estimate if really needed.

III. Damage Predictions

Although there have been clear occasions where plaster walls were cracked at low amplitudes which did not break any windows, the latter damages are most spectacular, pose some hazard, any usually generate the largest repair bills. A rough rule of thumb is that total damage claims are 40 percent greater than the window claims bill. It remains to predict glass damage versus predicted airblast amplitude.

In theory glass panes are treated as simply supported thin plates, uniformly loaded, so that maximum stress occurs near the center of the pane. The load or pressure at failure should be proportional to the pane area, inversely proportional to the square of the thickness, and proportional to the breaking stress of the particular glass. Laboratory tests, by Ansevin (26) at the Pittsburgh Plate Glass Company, have shown mean breaking stresses for various glasses to range from about $6,000 \mathrm{psi}$ to $30,000 \mathrm{psi}$ for rapid loading as in explosion airblast waves or sonic booms. There is, however, appreciable scatter in test results which has been described by McKinley (27) as a 25 percent standard deviation around the mean breaking stress. This may be useful to designers, interested in safety factors of two, and recommended by the Pittsburgh Plate Glass Company (28), but it is not adequate for nuisance damage prediction where $10^{-4}$

failure probabilities can create a large reaction in a city with 10 million window panes. The Gaussian distribution with 25 percent standard deviation gives total failure, $4 \sigma$, with about $4 \times 10^{-5}$ probability, under no load. There have not been enough glass test samples to adequately show just what the small probability distribution looks like, but a log-normal distribution assumption avoids the no-load breaking result. The distribution described by Weibul1 (29), 


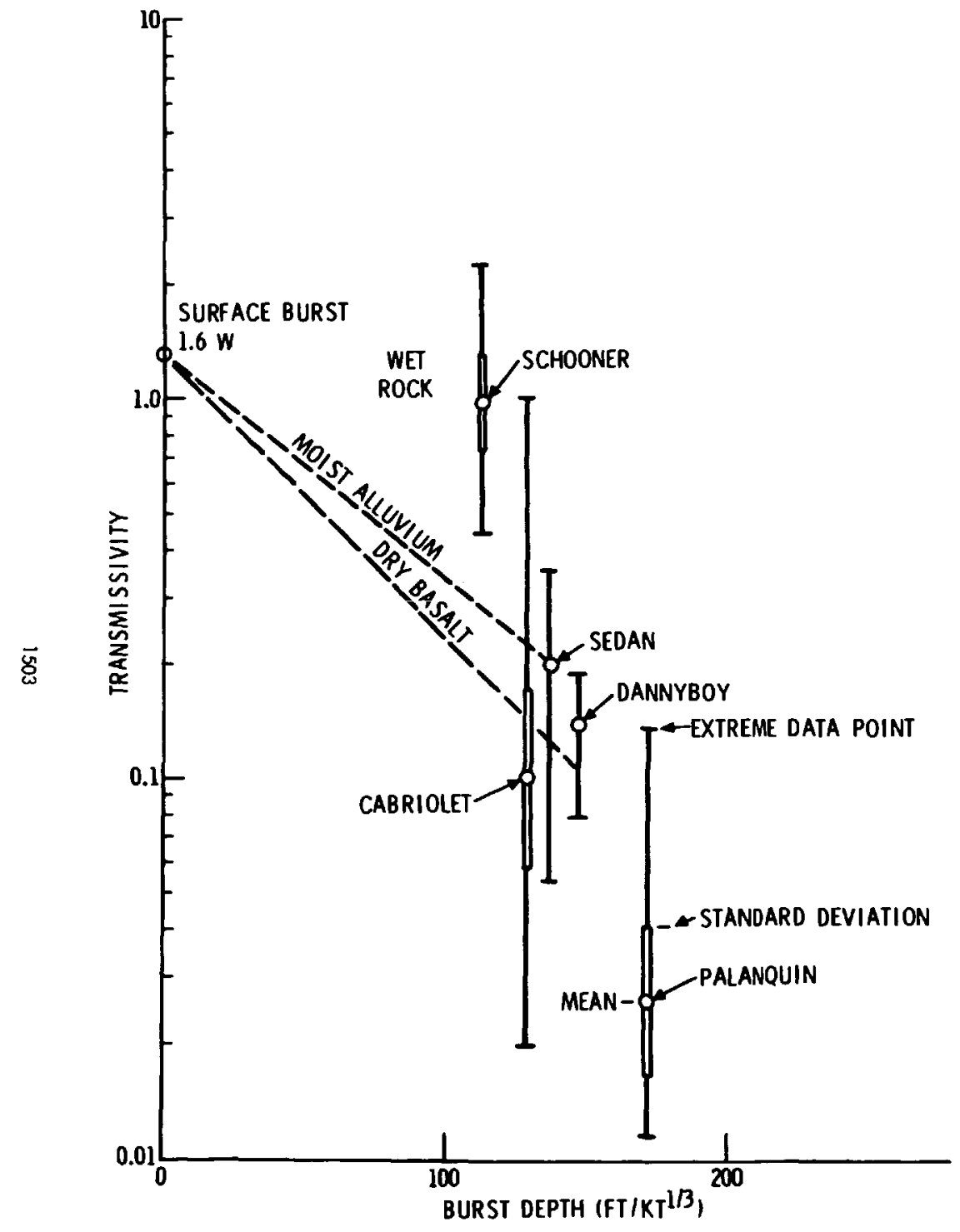

Fig. 20 Airblast Transmissivity from Underground Nuclear Tests.

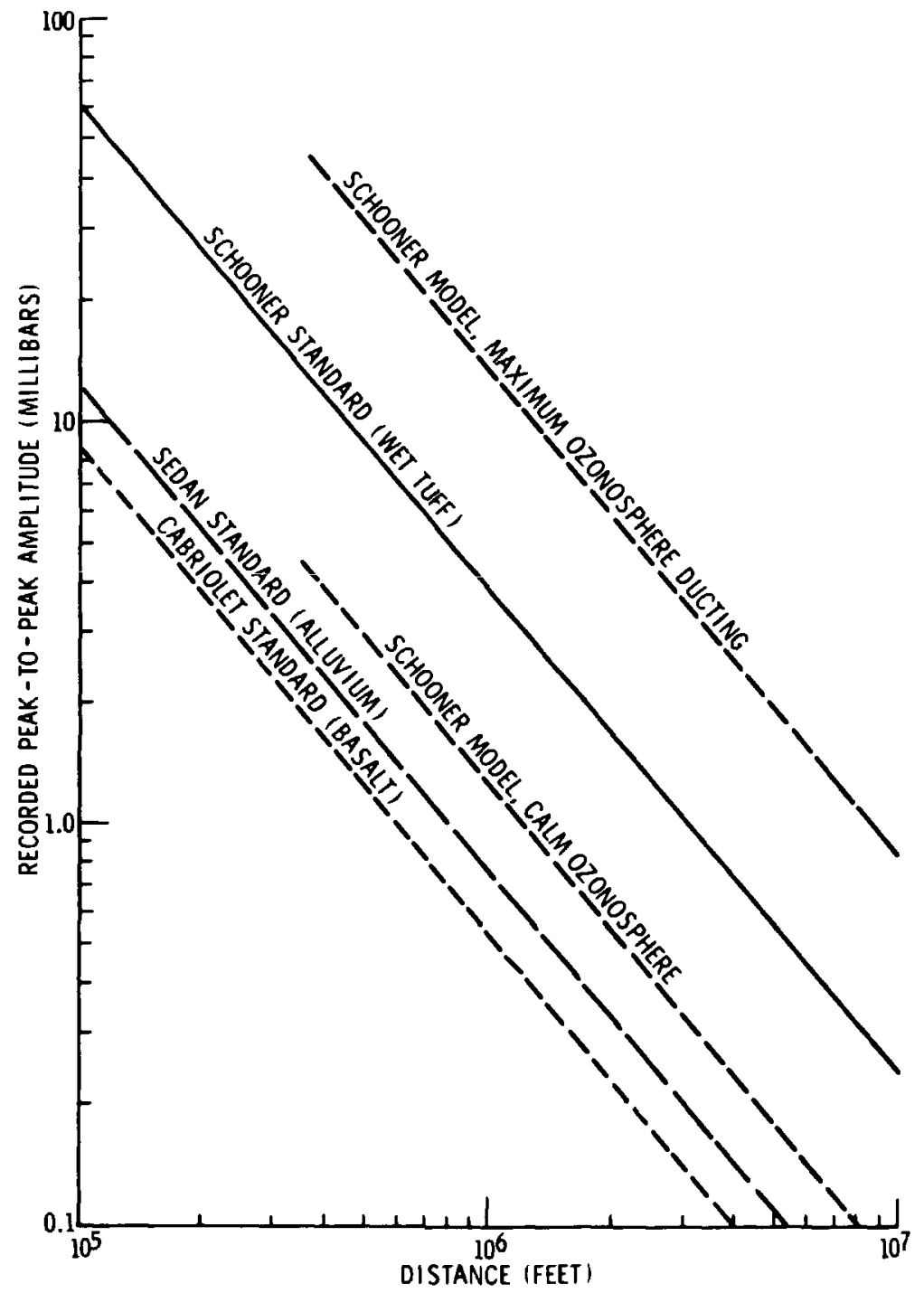

Fig: 21 Airblast Amplitudes for 1-Mt Crater Bursts. 
a weakest link model, may also be assumed, but again, there are yet insufficient data to show a better fit than is given by the log-normal.

Large pane areas are most vulnerable and they are further affected by resonances with sonic boom or explosion waves. Maximum deflections and stresses occur on the rebound, as shown by Wiggins (30), sometimes synchronous with the negative pressure phase. This has been verified by the multitude of occasions where large store windows wound up on the sidewalk. Back-chamber Helmholtz resonance may also contribute significantly, according to Seshadri (31), depending on the room or building protected by the glass pane. Rather complete calculated estimates have been made for sonic booms by Blume, et al (32), and Wiggins (33), with consideration of these factors plus assumed damping and directional exposure effects, to explain various damage incidents. To date some have given the right order of magnitude for breakage but there have been inconsistencies and credibility limitations with the simplified theory.

At this time, while awaiting expected improvements, damage predictions for Plowshare purposes may be made from the results of the Medina explosion described by Reed, Pape, Minor, and DeHart (34). An accidental explosion of 115,000 1bs. of chemical explosives near San Antonio, Texas brought claims for 3,644 broken panes in that city. Special weather data were obtained and a blast prediction calculation for refracted waves was made, giving an overpressure pattern which resembled the claims patterns. A census of total exposed panes, by pane area categories, was made that allowed final calculation of breakage probability versus pane area and incident overpressure. This result is summarized in Figure 23, for the distribution of pane sizes as counted in San Antonio. Applied to other incidents, the Medina relation often appears to work quite well but occasionally misses. Further work on this problem continues to be sponsored by the SST project (35), for it is most important to predicting damage from sonic booms.

Recent calculation, with Latin-American window pane census data, indicates that nuclear excavation of a sea level canal in 1979 would probably break 6,000 to 10,000 panes, at a cost of about $\$ 150,000$, from either the Panama-Darien route or the Colombia-Atrato route. This damage level for the entire series of salvos, spread over whatever the construction period turns out to be, only totals two to three times the accidental damage to San Antonio in 1963.

No one was hurt by broken glass in San Antonio. Breaking glass may be a hazard, though, for a sonic boom at the Air Force Academy graduation in 1968 broke 300 panes, cut 15 people, hospitalizing one, according to news report (35). This extreme example points up needs for concern, warnings necessary, and public relations required to counter airblast effects from Plowshare. 


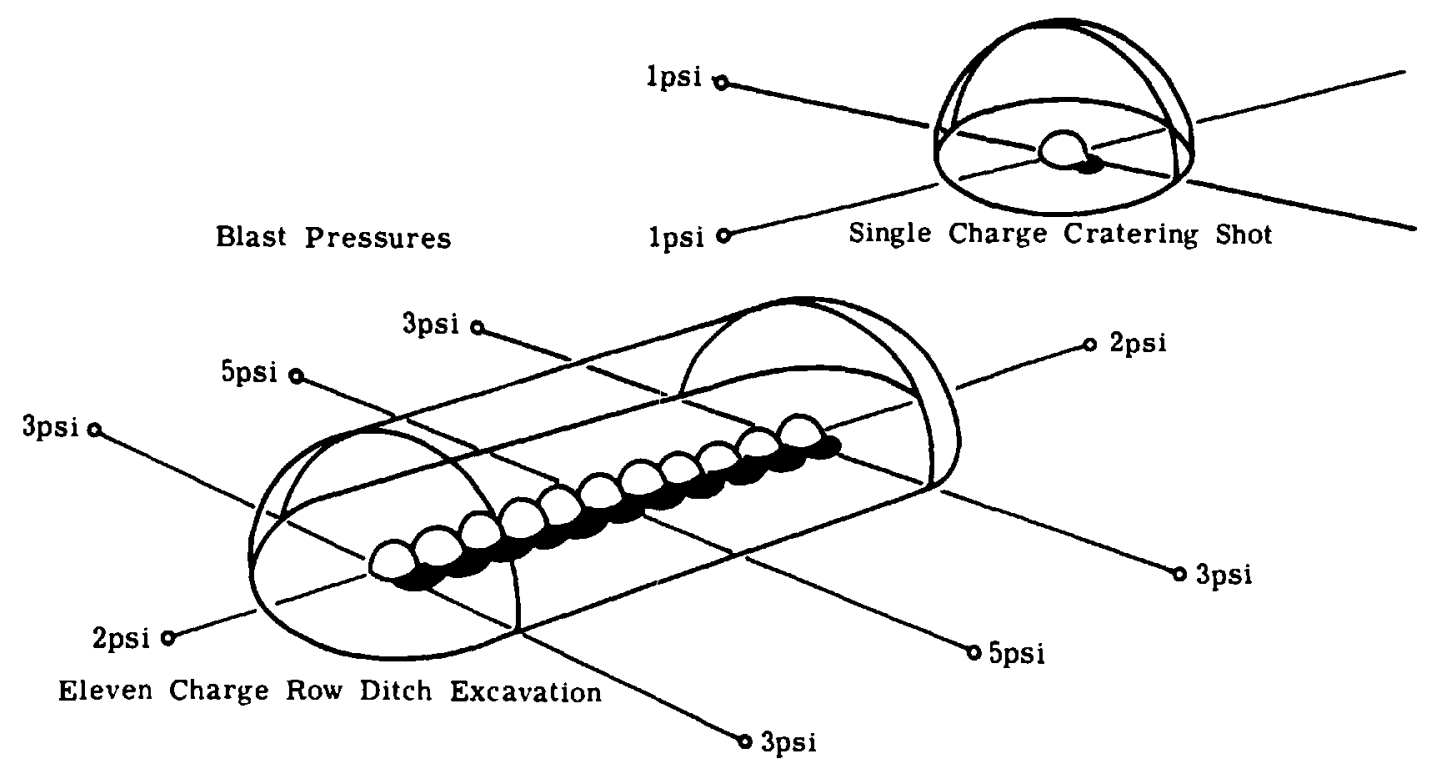

Fig. 22 Blast from Multiple Charges.

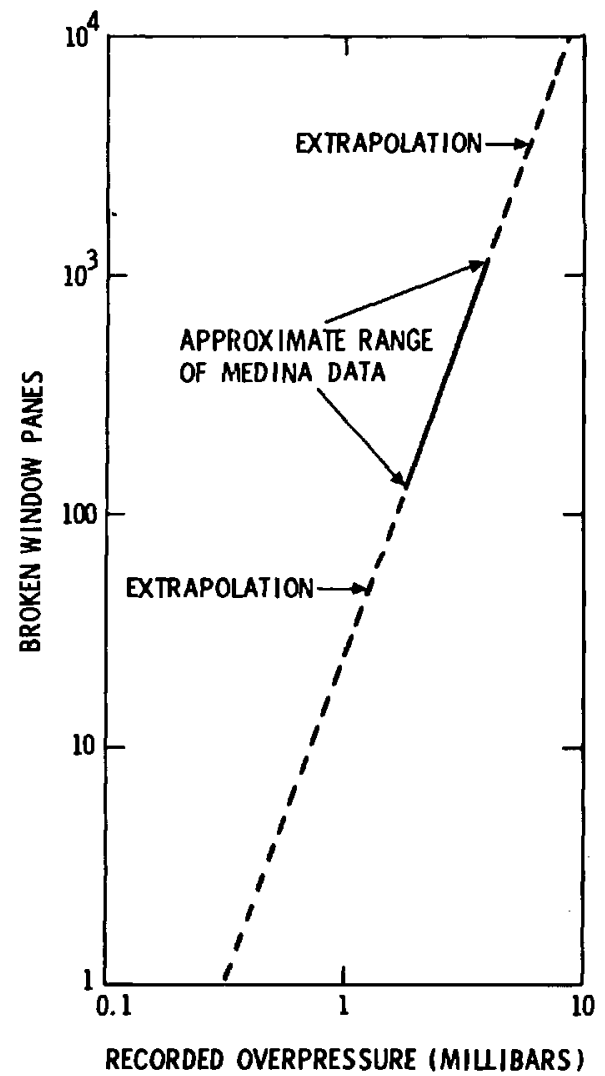

Fig. 23 Expected Window Damage versus Explosion

Blast Overpressure, 100,000

People Exposed. 


\section{REFERENCES}

1. Fujiwhara, S., "On the Abnormal Propagation of Sound," Bull. Cent. Meteor. Obs. Japan 2 (1) (1912).

2. Rothwell, P., "Calculation of Sound Rays in the Atmosphere," J. Acoust. Soc. Amer. 19, 205 (1947).

3. Cox, E. F., H. J. Plagge, and J. W. Reed, "Meteorology Directs Where Blast Will Strike," Bull. Am. Meteorol. Soc., Vol. 35, No. 3. pp. 95-103, March 1954.

4. Durham, H. B., "Raypac - A Special Purpose Analogue Computer," Sandia Corp. TM-46-55-54, March 24, 1955.

5. Thompson, R. J., "Sound Rays in the Atmosphere," Sandia Corp., SC-RR-64-1756, January 1965.

6. Thompson, R. J., "Computing Sound Ray Paths in the Presence of Wind," Sandia Corp., SC-RR-67-53, February 1967.

7. Lord Rayleigh, Theory of Sound, Sec. 270, Dover Publications, New York, 1945.

8. Byatt, W. J. and G. P. DeVault, "An Iteration Variation Method for Wave Propagation Problems," J. Geophys. Res., Vo1. 66, June 1961.

9. Cox., E. F., H. J. Plagge, and J. W. Reed, "Damaging Air Shocks at Large Distances from Explosions, Operation BusterJangle," Sandia Corp., WT-303, April 24, 1952.

10. Yacenda, A., "Congress Trio Hails War Games," Las Vegas Morning Sun, November 2, 1951.

11. U. S. Standard Atmosphere, 1962, NASA-USAF-USWB, U.S. Government Printing Office, Washington, December 1962 .

12. Sachs, R. G., "The Dependence of Blast on Ambient Pressure and Temperature," Report 466, Ballistic Research Laboratory, Aberdeen Proving Ground, Maryland, 1944.

13. The Effects of Nuclear Weapons, S. Glasstone, editor, Rev. Ed., DOD/AEC, U. S. Govt. Printing Office, Washington, D. C., April 1962 .

14. Broyles, C. D., "IBM Problem M Curves," SCTM-268-56(61), Sandia Corp., December 1, 1956.

15. Kelso, J. R., G. Stalk, and C. C. Clifford, Jr., "Project Banshee Field Operations," (1961 and 1962), Preliminary Report, DASA-543, Defense Atomic Support Agency, May 1963.

16. Reed, J. W., "Distribution of Airblast Amplitudes in the Ozonosphere Sound Rings," SC-M-69-33, Sandia Laboratories, February 1969 .

17. Whittaker, Maj. W. A., unpublished communication, U. S. Air Force Weapons Laboratory, Kirtland AFB, N. M., July 1969.

18. Lehto, D. L., and R. A. Larson, "Long Range Propagation of Spherical Shockwaves from Explosions in Air," NOL TR 69-88, U. S. Naval Ordnance Laboratory, to be published.

19. Viecelli, J., "Atmospheric Refraction and Focus of Blast Waves," J. Geophys. Res., Vo1. 72, No. 10, May 15, 1967.

20. Seckler, B. D. and J. B. Keller, "Geometrical Theory of Diffraction in Inhomogeneous Media," J. Acoust. Soc. Amer., Vo1. 31, pp. 192-216, 1959.

21. Barash, R. M., "Evidence of Phase Shift at Caustics," I. Acoust. Soc. Amer., Vo1. 43, pp. 378-380, 1968.

22. Buel1, C. E., unpublished communication, Kaman Nuclear, August 1969.

23. Reed, R. J., "Zonal Wind Behavior in the Equational S.tratosphere and Lower Mesosphere," J. Geophys. Res., Vo1. 71 , September $15,1966$.

24. Reed, J. W., "Amplitude Variability of Explosion Waves at 
Long Ranges," J. Acoust. Soc. of Amer., Vol. 39, No. 5, Pt. 1 , May 1966.

24a. Knox, J. B., and R. W. Terhune, "Calculation of Explosion Produced Craters-High Explosive Sources," UCRL-7738 (Rev. I), Lawrence Radiation Laboratory, Livermore, California, October 1964.

25. Vortman, L. J., "Close-in Air Blast from a Row Charge in Basalt," Project Dugout Final Report, PNE-608F, Sandia Corporation, Albuquerque, New Mexico, August 4, 1965.

26. Ansevin, R. W., "Correlation of the DSR with the Strength of Glass of Different Compositions and Configurations," Pittsburgh Plate Glass Company, Air Force Materials Laboratory, Wright-Patterson Air Force Base, Contract Report ML-TDR-04-180, August 1964.

27. McKinley, R. W. , "Response of Glass in Windows to Sonic Booms," Materials Research and Standards, Vo1. 4, No. 11, November 1964.

28. Glass Product Recommendations--Structural, Tech. Svc. Report, No. 101, Pittsburgh P1ate Glass Company, 1964.

29. Weibul1, W., "A Statistical Distribution Function of Wide Applicability," J. of App1. Mech., Vo1. 18, No. 3, September 1951.

30. Wiggins, J. H., Jr., Effects of Sonic Boom, J. H. Wiggins Company, Palos Verdes Estates, California, 1969.

31. Seshadri, T. V., "Transient Response of Mechano-Acoustica1 Networks," Doctoral Dissertation, Univ. of Oklahoma, May 1968.

32. Blume, J. A., R. L. Sharpe, J. Proulx, and E. G. Kost, "Response of Structures to Sonic Booms," Annex G, Part I, of NSBEO-1-67, National Sonic Boom Evaluation Office, July 28, 1967.

33. Wiggins, J. H., Jr., "The Effects of Sonic Boom on Structural Behavior," SST Report No. 65-18, Federal Aviation Agency, J. A. Blume and Associates, San Francisco, October 1965.

34. Reed, J. W., B. J. Pape, J. E. Minor, and R. C. DeHart, "Evaluation of Window Pane Damage Intensity in San Antonio Resulting from Medina Facility Explosion on 13 November 1963," Proceedings of Conference on Prevention and Protection Against Accidental Explosion of Munitions, Fuels and other Hazardous Materials, (10-13 October 1966), Annals of the New York Academy of Sciences, October 28, 1968.

35. Subcommittee on Physical Effects, Committee on sST-Sonic Boom, "Report on Physical Effects of the Sonic Boom," NAS-NRC, Washington, D. C., February 1968.

36. Albuquerque Journa1, "Boom Shatters 300 Windows," June 1 , 1968. 